\title{
Switching between Enantiomers by Combining Chromoselective Photocatalysis and Biocatalysis
}

Luca Schmermund, ${ }^{[a]}$ Susanne Reischauer, ${ }^{[b]}$ Sarah Bierbaumer, ${ }^{[a]}$ Christoph K. Winkler, ${ }^{[a]}$ Alba DiazRodriguez, ${ }^{[c]}$ Lee J. Edwards, ${ }^{[c]}$ Selin Kara, ${ }^{[\mathrm{d}]}$ Tamara Mielke, ${ }^{[\mathrm{e}]}$ Jared Cartwright, ${ }^{\text {[e] }}$ Gideon Grogan, ${ }^{\text {[e] }}$ Bartholomäus Pieber, ${ }^{*[b]}$ Wolfgang Kroutil*[a,f]

\begin{abstract}
Controlling the selectivity of a chemical reaction with external stimuli is common in thermal processes, but rare in visible-light photocatalysis. Here we show that the redox potential of a carbon nitride photocatalyst $(\mathrm{CN}-\mathrm{OA}-\mathrm{m})$ can be tuned by changing the irradiation wavelength to generate electron holes with different oxidation potentials. This tuning was the key to realizing photo-chemoenzymatic cascades that give either the $(S)$ - or the $(R)$-enantiomer of phenylethanol. In combination with an unspecific peroxygenase from Agrocybe aegerita, green light irradiation of CN-OA-m led to the enantioselective hydroxylation of ethylbenzene to ( $R$ )-1-phenylethanol $(99 \%$ ee). In contrast, blue light irradiation triggered the photocatalytic oxidation of ethylbenzene to acetophenone, which in turn was enantioselectively reduced with an alcohol dehydrogenase from Rhodococcus ruber to form (S)-1phenylethanol (93\% ee).
\end{abstract}

Many parameters influence the selectivity of a chemical reaction. ${ }^{[1]}$ For instance, catalytic reactions can be controlled by varying the catalyst/coordinated ligands, directing groups ${ }^{[2]}$ or by tuning external parameters (Scheme 1, A). ${ }^{[1 a, 3]}$ The selectivity of photochemical reactions varies with different wavelengths, ${ }^{[4]}$ but examples that use this for visible-light photocatalysis are rare. ${ }^{[5]}$

In one example, selective control between either a one- or two-fold substitution of 1,3,5tribromobenzene with $\mathrm{N}$-methylpyrrole using Rhodamin 6G (Rh-6G) as photocatalyst was demonstrated (Scheme 1, B) ${ }^{[5 a]}$ This selectivity switch is explained by the chromoselective generation of two photocatalytic species that differ in their reduction potential. Green light irradiation results in a common photoredox cycle and the expected mono-substituted product. In case of blue light, the Rh$6 \mathrm{G}$ radical anion, which is formed after quenching of Rh-6G* with a sacrificial electron donor, can absorb a second photon, resulting in the highly reducing $\mathrm{Rh}-6 \mathrm{G}^{-{ }^{*}}$ species that enables the formation of the di-substituted product. ${ }^{[5 a]}$

Here we show that electron holes with different oxidation potentials can be generated using a heterogeneous carbon nitride ( $\mathrm{CN}$ ) catalyst by changing the incident photon energy. The combination of this strategy with biocatalysis allowed us to selectively produce the $(S)$ - or $(R)$-enantiomer of a chiral alcohol in photo-chemo-enzymatic reaction sequences (Scheme 1C). 
A General Strategies to Control the Outcome of a Reaction

\section{A}

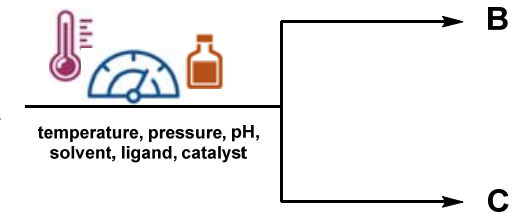

B Chromoselective access to different reduction potentials

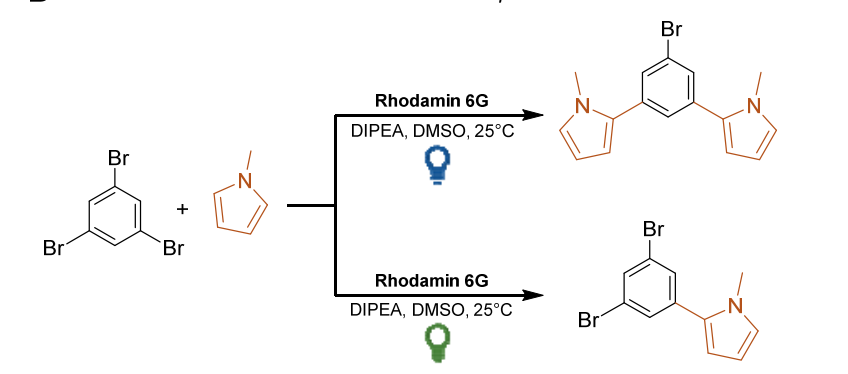

C This work:

Chromoselective control of oxidation potentials in photochemoenzymatic cascades

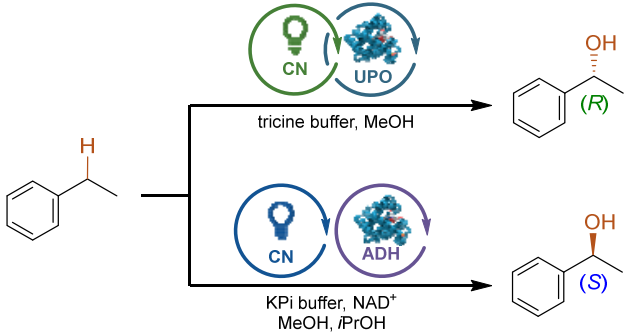

Scheme 1. A) General approaches to control of the outcome of a chemical reaction; B) Chromoselective control in photocatalytic $\mathrm{C}$ - $\mathrm{H}$-arylations ${ }^{[5 a]}$; C) This study: Chromoselective control of the stereochemical outcome of photo-chemo-enzymatic reactions.

We recently realized that the choice of the wavelength is crucial for high selectivities in metallophotocatalytic cross couplings using a heterogeneous carbon nitride material, which is made from urea and oxamide in molten salt $(\mathrm{CN}-\mathrm{OA}-\mathrm{m}) .^{[5 \mathrm{~b}, 5 \mathrm{c}, 6]}$ While this can be rationalized by a purely kinetic effect, there is also evidence that a wavelength-controlled generation of excited species with different oxidation potentials could be responsible for this phenomenon. CN-OA-m has a strong absorption up to $\sim 460 \mathrm{~nm}$ and a comparably weaker absorption band up to $\sim 700 \mathrm{~nm}$, which were ascribed as the $\pi-\pi^{*}$ and $n-\pi^{*}$ electron transitions, respectively (Figure $\left.1, A\right) \cdot{ }^{[7]}$ The selective induction of the $n-\pi^{*}$ electron transition using long wavelengths $(525 \mathrm{~nm})$ should result in electron holes with a lower oxidation potential compared to irradiation using blue light $(440 \mathrm{~nm})$. The choice of the wavelength should not affect the reduction potential of the electron that is promoted into the valence band. Although such a behavior was previously suggested, ${ }^{[7]}$ there is, to the best of our knowledge, no report that applies this concept for controlling the selectivity of chemical reactions.

We hypothesised that such a strategy would allow us to induce a photocatalytic reaction of a substrate with green light selectively in the presence of a second compound that is only photo-oxidized when shorter wavelengths are used. The photocatalytic aerobic oxidation of benzylic $\mathrm{sp}^{3} \mathrm{C}-\mathrm{H}$ bonds, which is feasible with other members of the carbon nitride family and blue light irradiation, ${ }^{[8]}$ served as a model reaction for our initial studies. In a series of experiments, we were indeed able to show that only blue light results in the desired carbonyl products and no reaction occurs at longer wavelengths (Figure 1, B). 

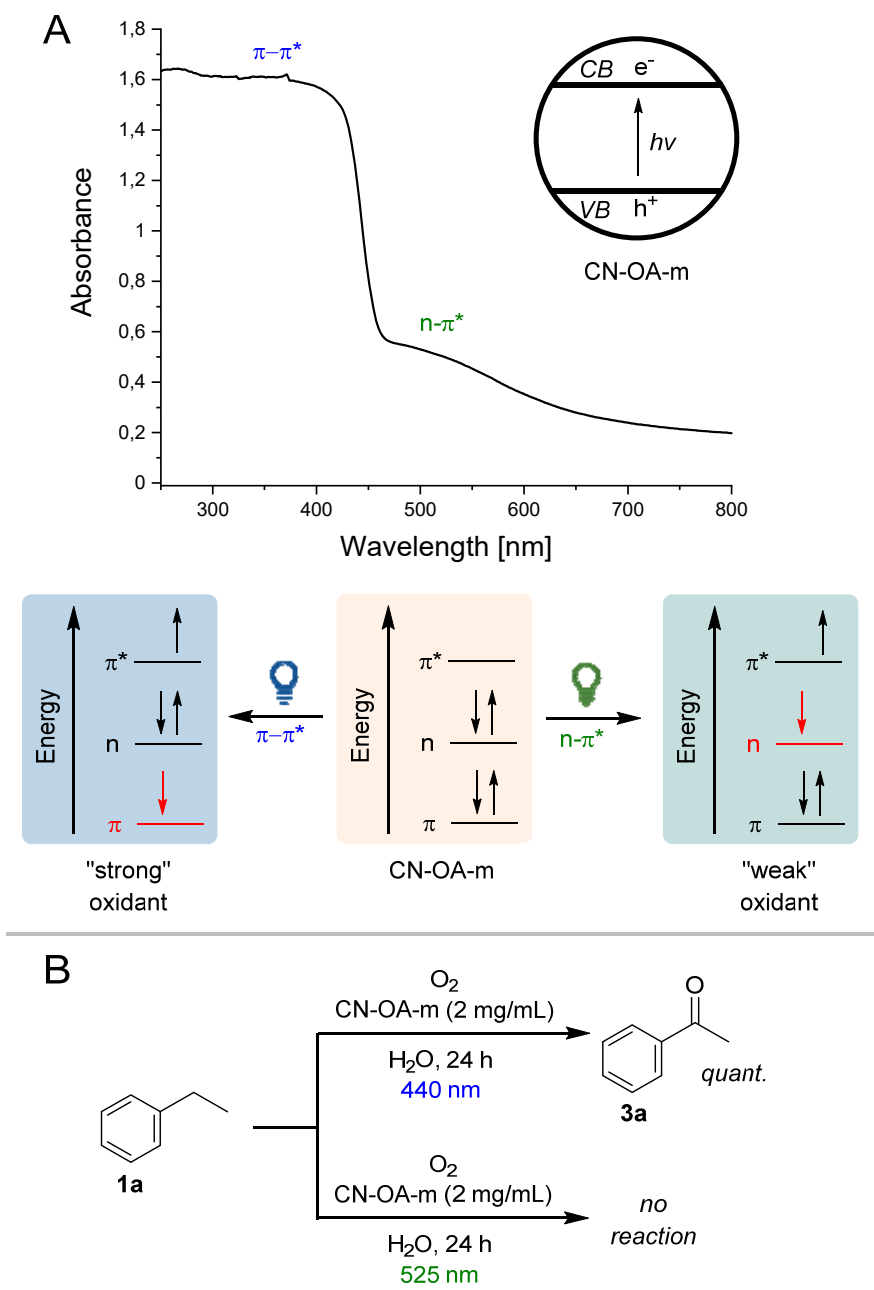

Figure 1. Chromoselective generation of excited CN-OA-m species with different oxidation potentials. A) Switching between $\pi-\pi^{*}$ and $n-\pi^{*}$ electron transitions using different wavelengths. B) The oxidation of ethylbenzene $1 \mathrm{a}$ to acetophenone $3 \mathrm{a}$ is only possible using blue light.

Carbon nitrides are used to catalyse the formation of $\mathrm{O}_{2}$ and $\mathrm{H}_{2}$ via water oxidation ${ }^{[9]}$ and the production of hydrogen peroxide from oxygen and alcohols, which requires the reduction of $\mathrm{O}_{2}{ }^{[10]}$ Hydrogen peroxide can then be used to fuel the enantioselective biocatalytic hydroxylation of ethylbenzene derivatives by the unspecific peroxygenase ${ }^{[11]}$ (UPO) from A. aegerita ${ }^{[12]}$ (AaeUPO). ${ }^{[13]}$

We hypothesized that a chromoselective activation of $\mathrm{CN}-\mathrm{OA}-\mathrm{m}$ with green light enables the selective formation of $\mathrm{H}_{2} \mathrm{O}_{2}$ in the presence of ethylbenzene (1) and the AaeUPO, which in turn catalyses the asymmetric hydroxylation of 1 (Figure 2). Performing the reaction in tricine buffer using $528 \mathrm{~nm}$ LEDs indeed resulted in a high selectivity towards $(R)$-1-phenylethanol formation $[(R)-2 \mathrm{a}$, up to $3.8 \mathrm{mM}, 98 \%$ $e e]$ with low amounts (3\%) of acetophenone (3a). When the same reaction was carried out using shorter wavelengths, 3a became the main product, thus supporting our hypothesis. Ketone (3a) formation was also the preferred reaction in the presence of blue light in phosphate buffer. 

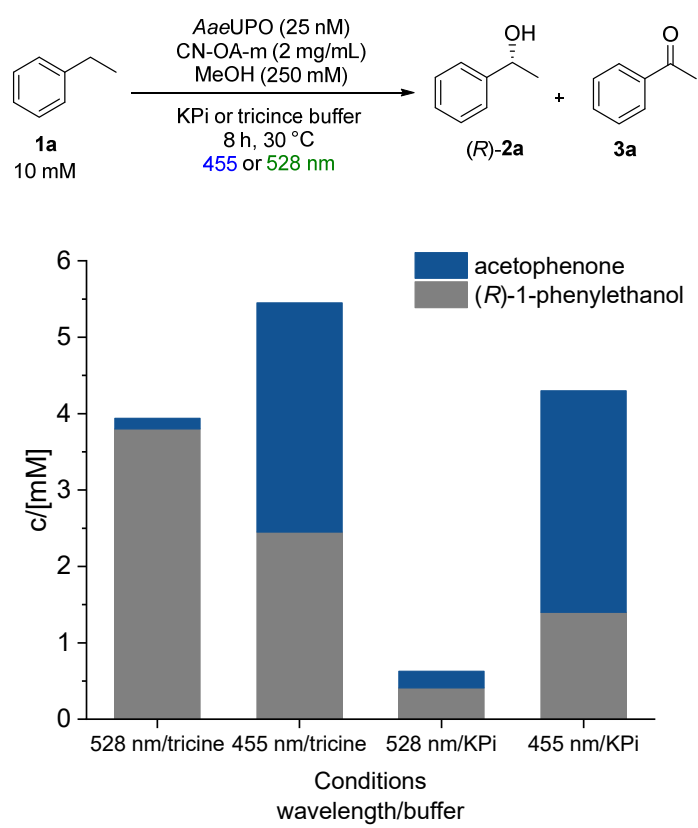

Figure 2. Influence of different wavelengths and buffers on the photoenzymatic hydroxylation of ethylbenzene; reaction conditions: AaeUPO (25 $\mathrm{nM}$ ), ethylbenzene (10 mM), CN-OA-m (2 mg mL-1), MeOH (250 mM), KPi (100 mM, pH 7.5) or tricine (100 mM, pH 7.5), $455 \mathrm{~nm}(1440 \mu \mathrm{mol}$ photons m $\left.{ }^{2} \mathrm{~s}^{-1}\right)$ or $528 \mathrm{~nm}\left(1330 \mu \mathrm{mol}\right.$ photons $\left.\mathrm{m}^{-2} \mathrm{~s}^{-1}\right), 30^{\circ} \mathrm{C}, 8 \mathrm{~h}$.

It was previously shown that UPOs are deactivated in the presence of blue light, a photocatalyst and $\mathrm{O}_{2}$ due to the generation of reactive oxygen species (ROS) that harm the enzyme. ${ }^{[14]}$ Consequently, one might expect that green light might be less harmful to the UPO and lead to higher conversions in comparison to blue light. To investigate this aspect, UPO and CN-OA-m were incubated for one hour in the presence of oxygen and green or blue light, before 1a was added (Figure S46). The mixture incubated at longer wavelengths indeed led to a higher conversion for the asymmetric hydroxylation after addition of $\mathbf{1 a}$.

The milder conditions subsequently allowed an extension of the substrate scope for AaeUPO (Scheme 2). Nine additional substrates were converted with high stereoselectivity ( $>98 \%$ e.e.) to the corresponding alcohols with concentrations of $1.0-6.0 \mathrm{mM}$. None of these ethylbenzene derivatives has been transformed with AaeUPO using an in situ $\mathrm{H}_{2} \mathrm{O}_{2}$ generation system before.

Ethylbenzenes bearing a methyl-substituent in the ortho- or meta-position were hydroxylated with 99\% regioselectivity at the ethyl group to give the desired chiral alcohols $(R)-\mathbf{2 b}$-c. This ability to distinguish between a methyl and an ethyl group has not been reported before. Acetophenone substituted with ethyl in the para-position (1i) allowed to access a bi-functionalised chiral hydroxyketone $\mathbf{2} \mathbf{i}$, which is otherwise difficult to make. The same is true for $\mathbf{2} \mathbf{j}$. 


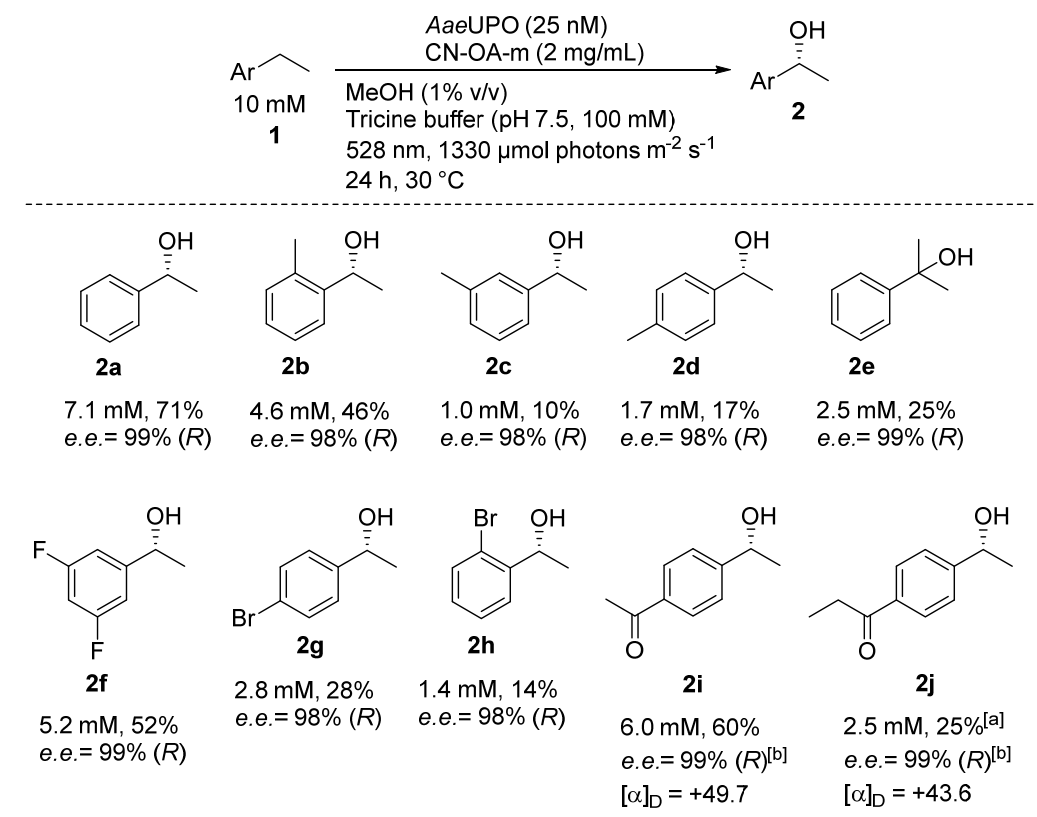

Scheme 2. Substrate scope of $A a e U P O$ using $\mathrm{H}_{2} \mathrm{O}_{2}$ generated by $\mathrm{CN}-\mathrm{OA}-\mathrm{m}$ under green light irradiation; Absolute configurations were determined by reference material; [a] $(R)$-enantiomer determined by measurement of the specific rotation $\left(20^{\circ} \mathrm{C}, c 1.00, \mathrm{CHCl}_{3}\right)$ and comparison to literature; [b] based on external calibration curves of $\mathbf{2} \mathbf{i}$.

Recycling experiments further showed that $\mathrm{CN}-\mathrm{OA}-\mathrm{m}$ can be reused by centrifugation and one washing step with water. CN-OA-m was reused three times after drying at room temperature (Figure S47-49). Transferring the photo-chemo-enzymatic hydroxylation from a total volume of $1 \mathrm{~mL}$ in $1.5 \mathrm{~mL}$ glass vials successfully to a larger scale $(7 \mathrm{~mL}$ volume, $10 \mathrm{~mL}$ tubes) in another photoreactor (provided by GlaxoSmithKline, S5), ${ }^{[15]}$ showed the robustness and reproducibility of the approach. The hydroxylation of 1a worked equally well giving up to $7.5 \mathrm{mM}$ of $(R)-2 \mathrm{a}$.

Finally, we sought to design a photo-chemo-biocatalytic cascade that yields the corresponding $(S)$ enantiomers by taking advantage of the chromoselective activation of CN-OA-m (Scheme 3). The bluelight mediated formation of ketone 3 a from 1a proceeds smoothly in KPi buffer and was successfully coupled with a subsequent biocatalytic reduction using an alcohol dehydrogenase (ADH-A) from Rhodococcus ruber. ${ }^{[16]}$ The optimized two-step one-pot procedure led to $2.5 \mathrm{mM}(S)$-2a with an e.e. of $93 \%$. The lower e.e. obtained in the photochemo-enzymatic cascade compared to previous reports by $\mathrm{ADH}-\mathrm{A}$ (e.e. $99 \%)^{[17]}$ can be explained by the formation of a small amount of rac-1-phenylethanol during the photocatalytic reaction under blue light irradiation. This cascade represents a stereocomplementary pathway compared to the pathway with AaeUPO using the same photocatalyst. Interestingly, it was noticed that $\mathrm{MeOH}$ was not required for the reaction to hydroxylate ethylbenzene with AaeUPO. Without $\mathrm{MeOH}$ the same concentration of product was detected. Thus, the reaction is possible without a sacrificial electron donor like $\mathrm{MeOH}$ or formate, which is in contrast to some examples reported in literature. ${ }^{[13 a, 18]}$ For practical reasons, $\mathrm{MeOH}$ was still used since it simplified the preparation of stock solutions of the hydrophobic substrates. 


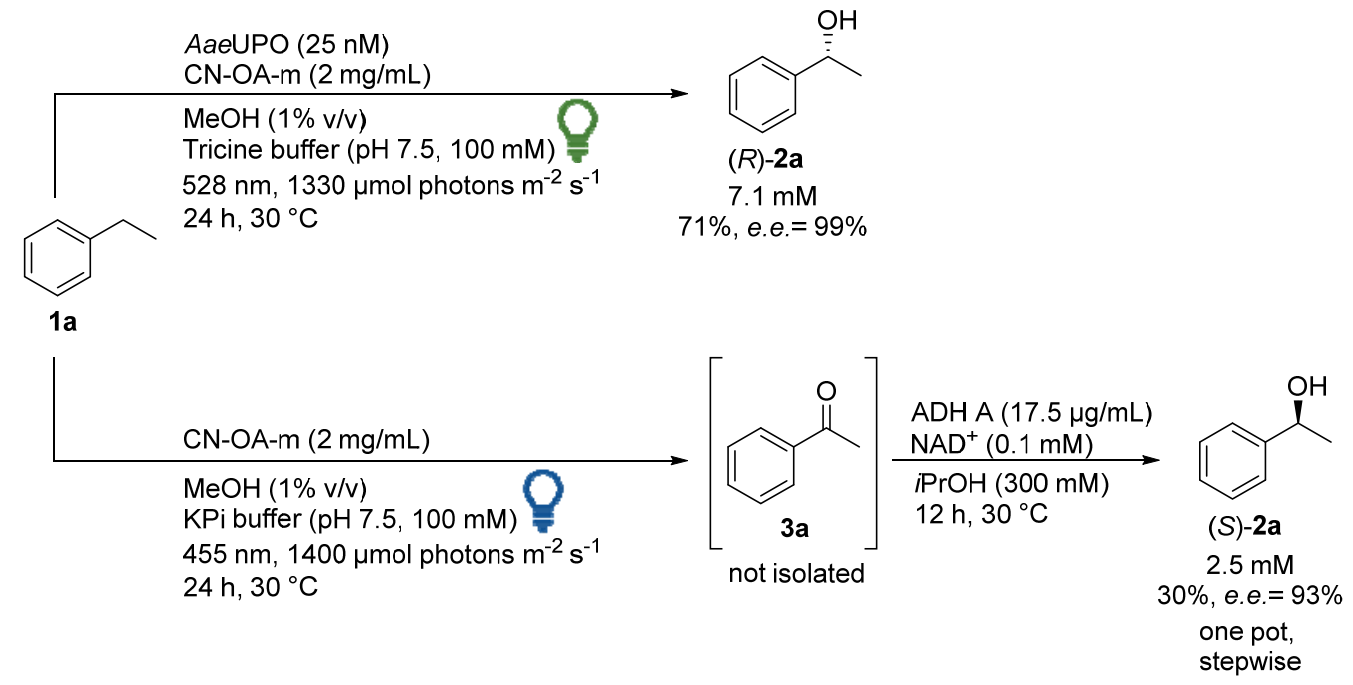

Scheme 3. Light-driven enantioselective oxyfunctionalizations of 1a by using chromoselective CN-OA-m and AaeUPO or ADH-A.

To the best of our knowledge this is the first example in which it was possible to utilize the same photocatalyst to either oxidize an organic substrate or to provide in situ formed $\mathrm{H}_{2} \mathrm{O}_{2}$ without photocatalytic oxidation of the substrate, all controlled only by the choice of the wavelength.

In summary, we showed that electron holes with different oxidation potentials can be generated using a carbon nitride material by simply changing the photon energy. In the presence of blue light this enables the oxidation of ethylbenzene to acetophenone in an aqueous solution. Using green light the organic substrate does not react and only $\mathrm{H}_{2} \mathrm{O}_{2}$ is formed. This was the key for designing chromoselective photo-chemo-enzymatic cascade reactions. Selective hydrogen peroxide generation enabled the hydroxylation of ethylbenzene to give $(R)$-1-phenylethanol $(R)-2 \mathrm{a}$ using an UPO, whereas the photocatalytic oxidation to acetophenone was coupled with an enantioselective reduction to (S)-1-phenylethanol (S)-2a by an ADH. Additionally, low energy photons (green light) increased the stability of UPO compared to blue light, which permitted the expansion of the substrate scope of this enzyme. Controlling the outcome of a photocatalytic reaction merely through the choice of wavelength employed presents exciting new options in reaction design and could be an important new tool for controlling reactivity and stereoselection in organic synthesis.

\section{Acknowledgements}

This project received funding from the European Union's Horizon 2020 research and innovation programme under the Marie SkłodowskaCurie grant agreement No 764920. S.B. acknowledges the Austrian Science Fund (FWF) for funding within the project CATALOX (DOC 46-B21). The University of Graz and the Field of Excellence BioHealth are acknowledged for financial support. We thank GlaxoSmithKline for providing the Photochemistry LED Illuminator (Pacer Components Ltd. Pangbourne, UK; housing machined by Rosper Engineering Co., Harlow, UK). S.R. and B.P. acknowledge the Max-Planck Society and the German Chemical Industry Fund (Liebig Fellowship, Fonds der Chemischen Industrie, $\mathrm{FCl}$ ) for generous financial support. B.P. thanks the Deutsche Forschungsgemeinschaft (DFG, German Research Foundation) under Germany's Excellence Strategy - EXC 2008 - 390540038 - UniSysCat for financial support. T.M. was funded by a studentship awarded by the industrial affiliates of the Centre of Excellence for Biocatalysis, Biotransformations and Biomanufacture (CoEBio3). We thank Prof. Klaus Zangger and Bernd Werner for recording of NMR spectra.

\section{References}

[1] a) T. Gaich, E. Winterfeldt, Directed Selectivity in Organic Synthesis: A Practical Guide, $1^{\text {st }}$ ed., Wiley-VCH Verlag GmbH \& Co. KGaA, Weinheim, 2014; b) G. Statham, Synthese 2017, 194, 4815-4838.

[2] a) I. Fleming, A. Barbero, D. Walter, Chem. Rev. 1997, 97, 2063-2192; b) C. Sambiagio, D. Schönbauer, R. Blieck, T. Dao-Huy, G. Pototschnig, P. Schaaf, T. Wiesinger, M. F. Zia, J. Wencel-Delord, T. Besset, B. U. W. Maes, M. Schnürch, Chem. Soc. Rev. 2018, 47, 6603-6743; c) G. Rousseau, B. Breit, Angew. Chem. Int. Ed. 2011, 50, 2450-2494; Angew. Chem. 2011, 123, 2498-2543; d) Z. Huang, G. Dong, Acc. Chem. Res. 2017, 50, 465-471.

[3] J. Jurczak, Physica B+C 1986, 139-140, 709-716.

[4] S. Protti, D. Ravelli, M. Fagnoni, Photochem. Photobiol. Sci. 2019, 18, 2094-2101.

[5] a) I. Ghosh, B. König, Angew. Chem. Int. Ed. 2016, 55, 7676-7679; Angew. Chem. 2016, 128, 7806-7810; b) S. Gisbertz, S. Reischauer, B. Pieber, Nat. Catal. 2020, 3, 611-620; c) C. Cavedon, E. T. Sletten, A. Madani, O. Niemeyer, P. H. Seeberger, B. Pieber, 2020; d) A. M. Martínez- 
Gualda, R. Cano, L. Marzo, R. Pérez-Ruiz, J. Luis-Barrera, R. Mas-Ballesté, A. Fraile, V. A. de la Peña O’Shea, J. Alemán, Nat. Commun. 2019, 10,2634

[6] B. Pieber, J. A. Malik, C. Cavedon, S. Gisbertz, A. Savateev, D. Cruz, T. Heil, G. Zhang, P. H. Seeberger, Ange. Chem. Int. Ed. 2019, 58, 9575-9580; Angew. Chem. 2019, 131, 9676-9681.

[7] G. Zhang, G. Li, Z.-A. Lan, L. Lin, A. Savateev, T. Heil, S. Zafeiratos, X. Wang, M. Antonietti, Angew. Chem. Int. Ed. 2017, 56, 1344513449; Angew. Chem. 2017, 129, 13630-13634.

[8] a) P. Geng, Y. Tang, G. Pan, W. Wang, J. Hu, Y. Cai, Green Chem. 2019, 21, 6116-6122; b) W. Zhang, A. Bariotaki, I. Smonou, F. Hollmann, Green Chem. 2017, 19, 2096-2100.

[9] W. J. Ong, L. L. Tan, Y. H. Ng, S. T. Yong, S. P. Chai, Chem. Rev. 2016, 116, 7159-7329.

[10] a) Y. Shiraishi, S. Kanazawa, Y. Kofuji, H. Sakamoto, S. Ichikawa, S. Tanaka, T. Hirai, Angew. Chem. Int. Ed. 2014, 53, 13454-13459; Angew. Chem. 2014, 126, 13672-13677; b) Y. Shiraishi, S. Kanazawa, Y. Sugano, D. Tsukamoto, H. Sakamoto, S. Ichikawa, T. Hirai, ACS Catal. 2014, 4, 774-780; c) Z. Wei, M. Liu, Z. Zhang, W. Yao, H. Tan, Y. Zhu, Energy Environ. Sci. 2018, 11, 2581-2589; d) X. Zeng, Y. Liu, Y. Kang, Q. Li, Y. Xia, Y. Zhu, H. Hou, M. H. Uddin, T. R. Gengenbach, D. Xia, C. Sun, D. T. McCarthy, A. Deletic, J. Yu, X. Zhang, ACS Catal. 2020, 10, 36973706 .

[11] a) Y. Wang, D. Lan, R. Durrani, F. Hollmann, Curr. Opin. Chem. Biol. 2017, 37, 1-9; b) M. Faiza, S. Huang, D. Lan, Y. Wang, BMC Evol. Biol. 2019, 19, 76; c) M. Hofrichter, R. Ullrich, Curr. Opin. Chem. Biol. 2014, 19, 116-125; d) M. Hobisch, D. Holtmann, P. Gomez de Santos, M. Alcalde, F. Hollmann, S. Kara, Biotechnol. Adv. 2020, 107615.

[12] a) P. Molina-Espeja, E. Garcia-Ruiz, D. Gonzalez-Perez, R. Ullrich, M. Hofrichter, M. Alcalde, Appl. Environ. Microbiol. 2014, 80, 34963507; b) P. Molina-Espeja, S. Ma, D. M. Mate, R. Ludwig, M. Alcalde, Enzyme Microb. Technol. 2015, 73-74, 29-33.

[13] a) W. Zhang, B. O. Burek, E. Fernandez-Fueyo, M. Alcalde, J. Z. Bloh, F. Hollmann, Angew. Chem. Int. Ed. 2017, 56, 15451-15455; Angew. Chem. 2017, 129, 15654-15658; b) L. Schmermund, V. Jurkaš, F. F. Özgen, G. D. Barone, H. C. Büchsenschütz, C. K. Winkler, S. Schmidt, R. Kourist, W. Kroutil, ACS Catal. 2019, 9, 4115-4144; c) B. O. Burek, S. Bormann, F. Hollmann, J. Z. Bloh, D. Holtmann, Green Chem. 2019, 21, 3232-3249; d) S. J. P. Willot, E. Fernández-Fueyo, F. Tieves, M. Pesic, M. Alcalde, I. W. C. E. Arends, C. B. Park, F. Hollmann, ACS Catal. 2019, 9, 890-894; e) F. Tieves, S. J.-P. Willot, M. M. C. H. van Schie, M. C. R. Rauch, S. H. H. Younes, W. Zhang, J. Dong, P. Gomez de Santos, J. M. Robbins, B. Bommarius, M. Alcalde, A. S. Bommarius, F. Hollmann, Angew. Chem. Int. Ed. 2019, 58, 7873-7877; Angew. Chem. 2019, 131, 79557959; f) Y. Ni, E. Fernández-Fueyo, A. G. Baraibar, R. Ullrich, M. Hofrichter, H. Yanase, M. Alcalde, W. J. H. van Berkel, F. Hollmann, Angew. Chem. Int. Ed. 2016, 55, 798-801; Angew. Chem. 2016, 128, 809-812; g) D. S. Choi, Y. Ni, E. Fernández-Fueyo, M. Lee, F. Hollmann, C. B. Park, ACS Catal. 2017, 7, 1563-1567; h) E. Churakova, M. Kluge, R. Ullrich, I. Arends, M. Hofrichter, F. Hollmann, Angew. Chem. Int. Ed. 2011, 50, 10716-10719; Angew. Chem. 2011, 123, 10904-10907; i) M. Hobisch, M. M. C. H. van Schie, J. Kim, K. R. Andersen, M. Alcalde, R. Kourist, C. B. Park, F. Hollmann, S. Kara, ChemCatChem 2020, 12, 4009-4013; j) J. Yoon, J. Kim, F. Tieves, W. Zhang, M. Alcalde, F. Hollmann, C. B. Park, ACS Catal. 2020, 5236-5242; k) W. Zhang, E. Fernandez-Fueyo, Y. Ni, M. van Schie, J. Gacs, R. Renirie, R. Wever, F. G. Mutti, D. Rother, M. Alcalde, F. Hollmann, Nat. Catal. 2018, 1, 55-62.

[14] a) S. Bormann, A. Gomez Baraibar, Y. Ni, D. Holtmann, F. Hollmann, Catal. Sci. Technol. 2015, 5, 2038-2052; b) B. O. Burek, S. R. d. Boer, F. Tieves, W. Zhang, M. van Schie, S. Bormann, M. Alcalde, D. Holtmann, F. Hollmann, D. W. Bahnemann, J. Z. Bloh, ChemCatChem 2019, $11,3093-3100$

[15] a) H. E. Bonfield, J. D. Williams, W. X. Ooi, S. G. Leach, W. J. Kerr, L. J. Edwards, ChemPhotoChem 2018, 2, 938-944; b) H. E. Bonfield, K. Mercer, A. Diaz-Rodriguez, G. C. Cook, B. S. J. McKay, P. Slade, G. M. Taylor, W. X. Ooi, J. D. Williams, J. P. M. Roberts, J. A. Murphy, L. Schmermund, W. Kroutil, T. Mielke, J. Cartwright, G. Grogan, L. J. Edwards, ChemPhotoChem 2020, 4, 45-51.

[16] K. Edegger, C. C. Gruber, T. M. Poessl, S. R. Wallner, I. Lavandera, K. Faber, F. Niehaus, J. Eck, R. Oehrlein, A. Hafner, W. Kroutil, Chem. Commun. 2006, 2402-2404.

[17] W. Stampfer, B. Kosjek, C. Moitzi, W. Kroutil, K. Faber, Angew. Chem. Int. Ed. 2002, 41, 1014-1017.

[18] M. M. C. H. van Schie, W. Zhang, F. Tieves, D. S. Choi, C. B. Park, B. O. Burek, J. Z. Bloh, I. W. C. E. Arends, C. E. Paul, M. Alcalde, F. Hollmann, ACS Catal. 2019, 9, 7409-7417. 